\title{
Integration of Chlorpyrifos Acetylcholinesterase Inhibition, Water Temperature, and Dissolved Oxygen Concentration into a Regional Scale Multiple Stressor Risk Assessment Estimating Risk to Chinook Salmon
}

\author{
Wayne G. Landis \\ Western Washington University \\ Valerie R. Chu \\ Western Washington University \\ Scarlett E. Graham \\ Western Washington University \\ Meagan J. Harris \\ Western Washington University \\ April J. Markiewicz \\ Western Washington University \\ Follow this and additional works at: https://cedar.wwu.edu/ietc_publications \\ Part of the Environmental Indicators and Impact Assessment Commons \\ See next page for additional authors
}

\section{Recommended Citation}

Landis, Wayne G.; Chu, Valerie R.; Graham, Scarlett E.; Harris, Meagan J.; Markiewicz, April J.; Mitchell, Chelsea J.; von Stackelberg, Katherine E.; and Stark, John D., "Integration of Chlorpyrifos Acetylcholinesterase Inhibition, Water Temperature, and Dissolved Oxygen Concentration into a Regional Scale Multiple Stressor Risk Assessment Estimating Risk to Chinook Salmon" (2019). IETC Publications. 5 .

https://cedar.wwu.edu/ietc_publications/5

This Article is brought to you for free and open access by the Categories at Western CEDAR. It has been accepted for inclusion in IETC Publications by an authorized administrator of Western CEDAR. For more information, please contact westerncedar@wwu.edu. 


\section{Authors}

Wayne G. Landis, Valerie R. Chu, Scarlett E. Graham, Meagan J. Harris, April J. Markiewicz, Chelsea J. Mitchell, Katherine E. von Stackelberg, and John D. Stark 


\title{
Health \& Ecological Risk Assessment
}

\section{Integration of Chlorpyrifos Acetylcholinesterase Inhibition, Water Temperature, and Dissolved Oxygen Concentration into a Regional Scale Multiple Stressor Risk Assessment Estimating Risk to Chinook Salmon}

\author{
Wayne G Landis, $*+$ Valerie $R$ Chu, $\dagger$ Scarlett E Graham, $\dagger$ Meagan J Harris, $\dagger$ April J Markiewicz, $\dagger$ \\ Chelsea J Mitchell, $\neq$ Katherine $E$ von Stackelberg, $\S$ and John D Stark $\neq$ \\ IInstitute of Environmental Toxicology, Huxley College of the Environment, Western Washington University, Bellingham, \\ Washington, USA \\ $\$$ Puyallup Research and Extension Center, Washington State University, Puyallup, Washington, USA \\ §Center for Health and the Global Environment, Harvard University, TH Chan School of Public Health, Boston, Massachusetts, USA
}

\begin{abstract}
We estimated the risk to populations of Chinook salmon (Oncorhynchus tshawytscha) due to chlorpyrifos (CH), water temperature (WT), and dissolved oxygen concentration (DO) in 4 watersheds in Washington State, USA. The watersheds included the Nooksack and Skagit Rivers in the Northern Puget Sound, the Cedar River in the Seattle-Tacoma corridor, and the Yakima River, a tributary of the Columbia River. The Bayesian network relative risk model (BN-RRM) was used to conduct this ecological risk assessment and was modified to contain an acetylcholinesterase (AChE) inhibition pathway parameterized using data from $\mathrm{CH}$ toxicity data sets. The completed BN-RRM estimated risk at a population scale to Chinook salmon employing classical matrix modeling runs up to 50-y timeframes. There were 3 primary conclusions drawn from the modelbuilding process and the risk calculations. First, the incorporation of an AChE inhibition pathway and the output from a population model can be combined with environmental factors in a quantitative fashion. Second, the probability of not meeting the management goal of no loss to the population ranges from $65 \%$ to $85 \%$. Environmental conditions contributed to a larger proportion of the risk compared to $\mathrm{CH}$. Third, the sensitivity analysis describing the influence of the variables on the predicted risk varied depending on seasonal conditions. In the summer, WT and DO were more influential than $\mathrm{CH}$. In the winter, when the seasonal conditions are more benign, $\mathrm{CH}$ was the driver. Fourth, in order to reach the management goal, we calculated the conditions that would increase juvenile survival, adult survival, and a reduction in toxicological effects. The same process in this example should be applicable to the inclusion of multiple pesticides and to more descriptive population models such as those describing metapopulations. Integr Environ Assess Manag 2020;16:28-42. @ 2019 SETAC
\end{abstract}

Keywords: Bayesian network relative risk model Population modeling Ecological risk assessment AChE inhibition Landscape scale risk assessment

\section{INTRODUCTION}

We demonstrate that a probabilistic ecological risk assessment, as exemplified by the Bayesian network relative risk model (BN-RRM), can integrate a biomarker, specifically acetylcholinesterase (AChE) inhibition, with other multiple stressors and population modeling to estimate risk to an endpoint. First, we describe the process of integrating the biomarker, the descriptions of other stressors, and population models into a BN-RRM. Then we illustrate how such an approach can be used to describe and compare risk due to exposure to chlorpyrifos $(\mathrm{CH})$, an organophosphate (OP)

This article contains online-only Supplemental Data

* Address correspondence to wayne.landis@wwu.edu

Published 5 August 2019 on wileyonlinelibrary.com/journal/ieam. pesticide, in combination with the water quality parameters, temperature, and dissolved oxygen (DO), to Chinook salmon (Oncorhynchus tshawytscha) populations. We use site-specific data from the Nooksack, Skagit, Cedar, and Yakima watersheds in Washington State, USA to estimate risk and to evaluate the contributions of the pesticide and water quality inputs. We demonstrate that our approach can be used to explore multiple stressors that can be integrated to estimate risk at a population scale.

\section{Bayesian network relative risk model}

The original relative risk model (RRM) was developed to address ecological risks associated with multiple stressors acting on diverse endpoints over larger spatial and longer temporal scales (Colnar and Landis 2007; Landis and Wiegers 2007) and has been applied worldwide (Bartolo 
et al. 2012; Chen et al. 2012; Apitz 2013; Kanwar et al. 2015). In the RRM the formation of the conceptual model uses the source-stressor-habitat-effect-impact framework that incorporates spatial relationships to indicate causal interactions (Landis and Wiegers 1997; Wiegers et al. 1998).

Ayre and Landis (2012) demonstrated that the causal framework of the RRM translates easily into the tiered node structure of a BN. Key attributes of BNs include their ability to incorporate a wide variety of data and to represent complex interactions such as those described by mechanistic representations of toxicity. Bayesian networks have been applied to environmental management and risk assessment (Marcot et al. 2006; Pollino et al. 2007; Uusitalo 2007; Barton et al. 2012) to guide research and monitoring to support decision making and resource management (Nyberg et al. 2006; Carriger and Newman 2011). Since 2012 , the utility of the integrated BN-RRM has been applied in numerous contexts, including contaminated sites (Hines and Landis 2014; Landis, Ayre et al. 2017), emergent disease (Ayre et al. 2014), nonindigenous species (Herring et al. 2015), and forestry management (Ayre and Landis 2012). A series of papers estimating risk due to $\mathrm{Hg}$ contamination and other factors in the South River in Virginia, USA demonstrated the applicability of the BN-RRM to estimate risk to organisms and water quality (Landis, Ayre et al. 2017), human health and well-being (Harris et al. 2017), and the evaluation of management alternatives and adaptive management (Johns et al. 2017; Landis, Markiewicz et al. 2017).

Risk, biomarkers, adverse outcome pathways, and population models

In an ecological risk assessment, the mechanisms of toxicity and the effects on survival, growth, and reproduction need to be placed in an ecological context. Hooper et al. (2013) incorporated an ecological context with regard to the response to climate change by identifying 2 processes, the induction of climate-induced toxic sensitivity and toxicantinduced climate sensitivity. Endpoints in ecological risk assessment are often stated as a population-scale property for a valued species. There are a few studies linking biomarkers such as AChE inhibition or other adverse outcome pathways with population models to estimate effects (Kramer et al. 2011; Miller et al. 2015; Conolly et al. 2017). However, these studies have been based on using a deterministic rather than probabilistic approaches, have not incorporated multiple ecological inputs or endpoints, nor have quantitatively evaluated uncertainty and model sensitivity.

In the present study, AChE inhibition was used as the initial measure of toxicity due to exposure to OPs in pesticides. Because data were available, we were able to extrapolate directly from AChE inhibition to effects, mortality, and swimming rate, which affect population dynamics.

We estimated the population size of Chinook salmon using age-structured population models. Hanson and Stark (2012) demonstrated the applicability of population models, applying Leslie matrix models to the estimate of population- scale effects. We used the same Leslie matrix approach to translate AChE inhibition effects on individual salmon reproduction and survival to changes in population number and age structure.

We also included ecological inputs, specifically water temperature (WT) and DO, to provide ecological context and to examine the relative contributions of habitat and toxicant to risk.

The following sections describe the methods used in incorporating the AChE inhibition pathway into the BN-RRM structure to calculate risk to populations of Chinook salmon and to detail our findings. The contributions to risk to Chinook salmon from exposure to $\mathrm{CH}$ under seasonal (summer and winter) variations in WT and DO were estimated, and the variability in risk was compared among the populations in the 4 watersheds in Washington State. We came to 3 major conclusions.

1) It is possible to translate the environmental concentration of a pesticide to effects, via the inhibition of $\mathrm{AChE}$, on subsequent mortality and behavioral changes in Chinook salmon, to the estimate of risk to a population.

2) The contributions of $\mathrm{CH}, \mathrm{WT}$, and $\mathrm{DO}$ to risk differed during seasons in each of the rivers. Patterns of risk were similar within each of the 4 rivers.

3) The framework should be amenable to the inclusion of other pesticide mixtures, additional environmental conditions, and populations as part of a metapopulation.

\section{METHODS}

\section{Study watersheds}

To demonstrate the usefulness of the integration of the AChE inhibition into the BN-RRM we needed appropriate case studies. The rivers in the case study watersheds should be spawning sites of Chinook salmon and have detailed information on pesticide concentrations and environmental factors. Seasonal monitoring data were an important factor in constructing the BN-RRM given that environmental factors and pesticide use varies with season. We wanted case study locations in the agricultural areas of Whatcom and Skagit counties in northwestern Washington, in an urban watershed, and in one that was representative of the Columbia River basin. We chose the Nooksack and Skagit rivers in Northwest Washington, the Cedar River in the urban Seattle-Tacoma corridor, and the Yakima River, a tributary of the Columbia on the eastern slopes of the Cascades (Figure 1).

All 4 rivers are impaired due to exceedances of water quality standards for temperature, DO, and $\mathrm{pH}$ (Ecology 2018). They have also been listed as impaired for exceedances of the OP pesticide $\mathrm{CH}$ under section 303(d) or 305(b) of the Clean Water Act (Ecology 2018). Specifically, the Nooksack and lower Yakima rivers are federally listed under Section 305(b) of the Clean Water Act as having CH concentrations at levels of concern to the health of aquatic 


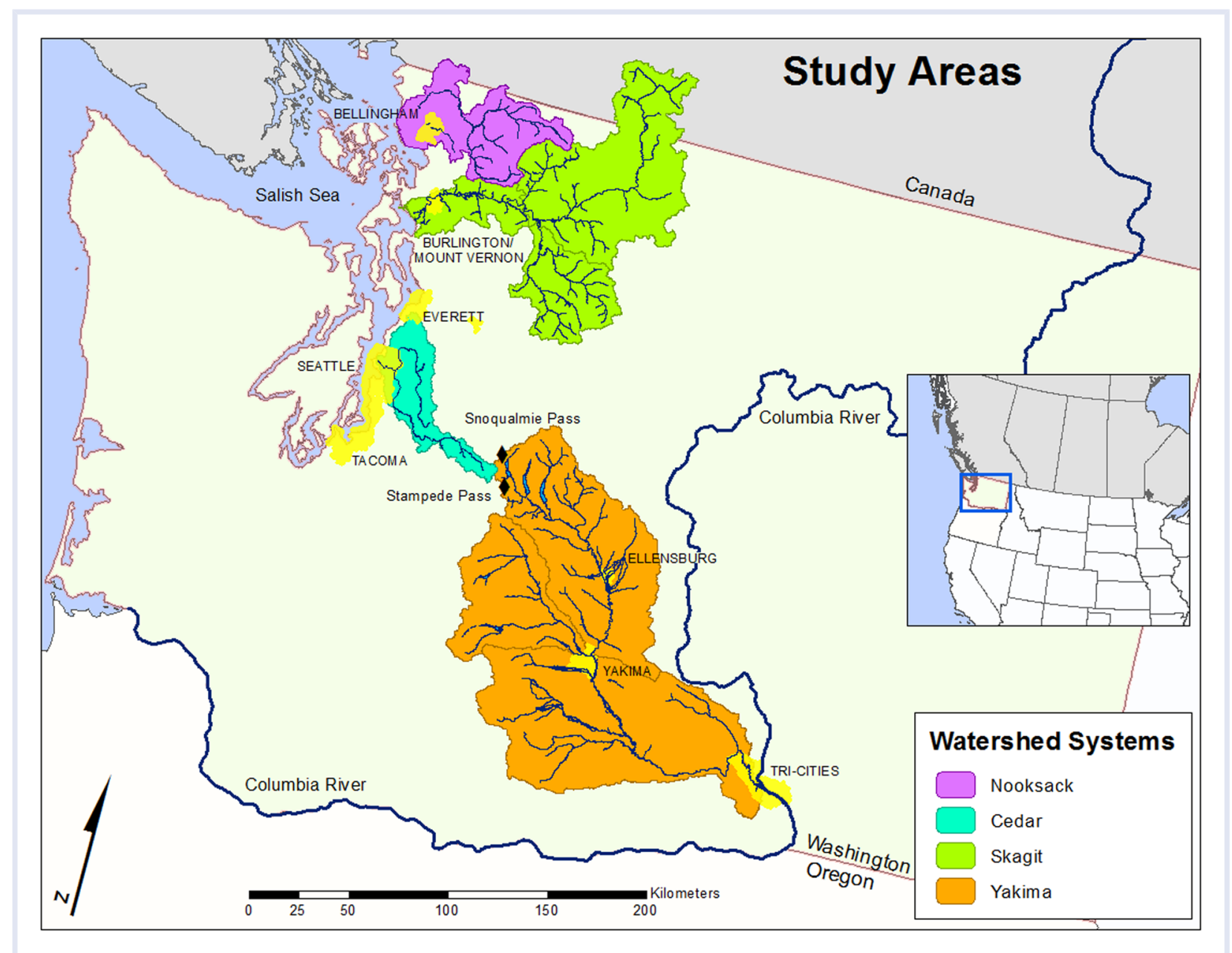

Figure 1. Map of the sites for the 4 study areas. The Nooksack, Cedar, and Skagit watersheds drain into the Puget Sound, Washington, USA. The Yakima is part of the Columbia River Basin. The urban areas are depicted in yellow.

and/or marine organisms (Ecology 2018). The Cedar River is federally listed under Section 303(d) of the Clean Water Act for $\mathrm{CH}$ concentrations that violate water quality standards (Ecology 2018).

The lower Skagit River basin is not federally listed as impaired. However, based on surface-water monitoring conducted in 2003 by the Washington State Department of Ecology (Ecology) and Department of Agriculture (WSDA), in 2008 the National Oceanic and Atmospheric Administration's (NOAA's) National Marine Fisheries Service (NMFS) recommended more extensive surface-water monitoring. The $\mathrm{OP}$ pesticides $\mathrm{CH}$, diazinon, and malathion specifically were identified for further measurement (Sargeant and Anderson 2010).

\section{Endpoint Chinook salmon}

Chinook (O. tshawytscha) have been selected as one of the Puget Sound indicators by the Puget Sound Partnership (PSP 2014). The indicators were selected as measures of the progress of the agency in its goal to restore and protect the Puget Sound. The management goal for the Chinook indicator is no net loss of the population.
Based on its selection as a Puget Sound indicator and the extensive Chinook data in the literature, the endpoint entity for each case study was the Chinook salmon with the attribute of no net loss of the population. We defined no net loss as a population maintained at or above 500000 individual fish for each of the case study sites as determined by population modeling. Baldwin et al. (2009) used this number as an initial population size in their modeling studies. In a population of 500000 fish, only 1382 were age 3-, 4-, and 5-y-old spawners (Baldwin et al. 2009). Additional details on the population model can be found in Supplemental Data file Population Modeling and Derivation of the Baldwin-Mitchell Model (BMM).

\section{Stressors}

Chlorpyrifos was chosen as the example OP pesticide stressor. The pesticide was detected in every watershed, and extensive data sets exist. Sandahl et al. (2005) and Laetz et al. $(2009,2013,2014)$ have demonstrated the toxicity of $\mathrm{CH}$ to Coho salmon and have characterized the exposureresponse relationships. Dissolved oxygen and WT were the ecological stressors noted for each of the rivers. Extensive 
data sets of all 3 stressors were available. Supplemental Data Table S1 contains the links to the databases. The number of records ranges from a low of 2690 cases for DO from the Lower Yakima to a high of 55978 for temperature in the Cedar. Multiple sites were observed in each watershed and the databases from the downloaded information are available upon request.

Description of the Bayesian network relative risk model

Relative risk conceptual model. The basic format of the RRM has been published previously (Landis and Wiegers 1997; Wiegers et al. 1998) (Figure 2A). The RRM was invented to incorporate multiple stressors and link them to multiple endpoints within a landscape. The RRM risk assessments are spatially explicit, with the study area divided into risk regions (Landis and Wiegers 2007). In each risk region there are sources of stressors that exist within the location or habitat that, upon release of those stressors, result in endpoints being exposed and adverse effects being generated. Ranks are used so that the combinations of sources, stressors, habitats, and effects all using different metrics can be combined into a final distribution of risk rankings (Landis and Wiegers 1997; Wiegers et al. 1998; Colnar and Landis 2007).

We used 4 watersheds (Skagit, Nooksack, Cedar, Yakima) as our risk regions within the Puget Sound study area (Figure 2B). The stressors used in this formulation were the concentrations of $\mathrm{CH}$ and DO, as well as WT. The endpoint was the probability distribution of the size of the Chinook population over time.

Chlorpyrifos was our chemical stressor. Numerous environmental factors also affect population growth of salmonids. However, the amount and quality of information regarding these factors varied between each of the watersheds. As a surrogate for more detailed information, we chose WT and DO as the environmental variables. Longterm water quality monitoring data were available for each of these parameters in all 4 of the watersheds. Moreover, both of these variables are known to affect salmon and can be described. Probability distributions for each variable were constructed for each watershed.

In the model, the watershed is the risk region in which the sources of each stressor are located. The activities or factors in each watershed that control the 3 stressors are land use practices, specifically, agriculture and therefore pesticide use, as well as seasonal effects on WT and DO. The habitat is Chinook habitat used for migration to and from the sea, as well as for rearing areas and spawning grounds. The effects are the OP-affected biochemical pathways in salmonids that result in changes in swimming rates and mortality. Changes in WT affect DO concentrations that, singly and combined, can affect salmonid reproduction and survivorship. The impact was the probability of the Chinook population being below that desired population size for a specific watershed.

We have presented a more detailed conceptual model in Figure $2 \mathrm{C}$ to represent the cause-effect pathways in detail and to show how the 3 stressors can cause combined effects to Chinook salmon. In this diagram, the specific watershed is listed as the source. Agricultural practices, specifically OP use, were determined on the basis of seasonal applications. We also had sufficient data to describe the distribution of DO concentrations and changes in WT by season. Again, we were focusing on those areas where Chinook occur in the habitat by season.

There were 4 main categories of effects used: Toxicological Effects (extrapolated from AChE Inhibition), as well as Juvenile Effects, Egg to Emergence Effects, and Adult Effects, which were determined by DO concentrations and WT. Juvenile Survival and Adult Survival were 2 parameters critical in determining the population dynamics of the Chinook salmon. An impact was defined as the change in the probability of the population size probability distribution at each time interval as compared to the current state model that began at 500000 fish. Impacts to Juvenile Survival were determined by Toxicological Effects, Juvenile Effects, and Egg to Emergence Effects. Adult Survival was determined by Adult Effects.

The segment of the conceptual model describing an AChE inhibition can be found as the insert in Figure 2A. The AChE inhibition was estimated from an exposure-response curve fitted to experimental data supplied by Laetz et al. (2009). The organismal scale responses described in our study were mortality and inhibition of swimming activity. In the conceptual model (Figure 2B) these events were represented as nodes from AChE inhibition to changes in swimming rates and mortality. These pathways were eventually combined to describe the totality of toxicological effects.

We portray the completed conceptual model in Figure 3A. The specific watershed (Skagit), OP (CH), and season (winter) are specified under Source. In the box is a diagram of the pathway used to describe Toxicological Effects. The measured OP concentration was converted to AChE inhibition, considered a key event in the toxicity of these OP compounds. Percent mortality was estimated next, along with the alteration of swimming rates. Juvenile fish that cannot swim do not escape predators and are less likely to migrate to suitable habitat. The outputs from both of these nodes were combined into a toxicity node to provide an indication of the total effect of the OP on juveniles. The state of the population was estimated at $1,5,10,20$, and $50 \mathrm{y}$. Five years is the maximum lifespan (generation time) of the Chinook, so these times represent $<1,1,2,4$, and 10 generations.

Figure 3B is the BN-RRM, as depicted in Netica (Norsys 2014), describing risks to Chinook salmon. This graphic represents the completed calculation of risk to Chinook salmon in the Lower Skagit River watershed in winter season, based on measured concentrations of $\mathrm{CH}, \mathrm{DO}$, and WT measurements. The key event in the pesticide pathway is AChE inhibition, the effects of which are summarized in the Toxicological Effects pathway. In this model, 3 of the nodes were used to specify the source or habitat: the watershed (1), the season (2), and the year for which the simulation was set (3). All other nodes present probability 


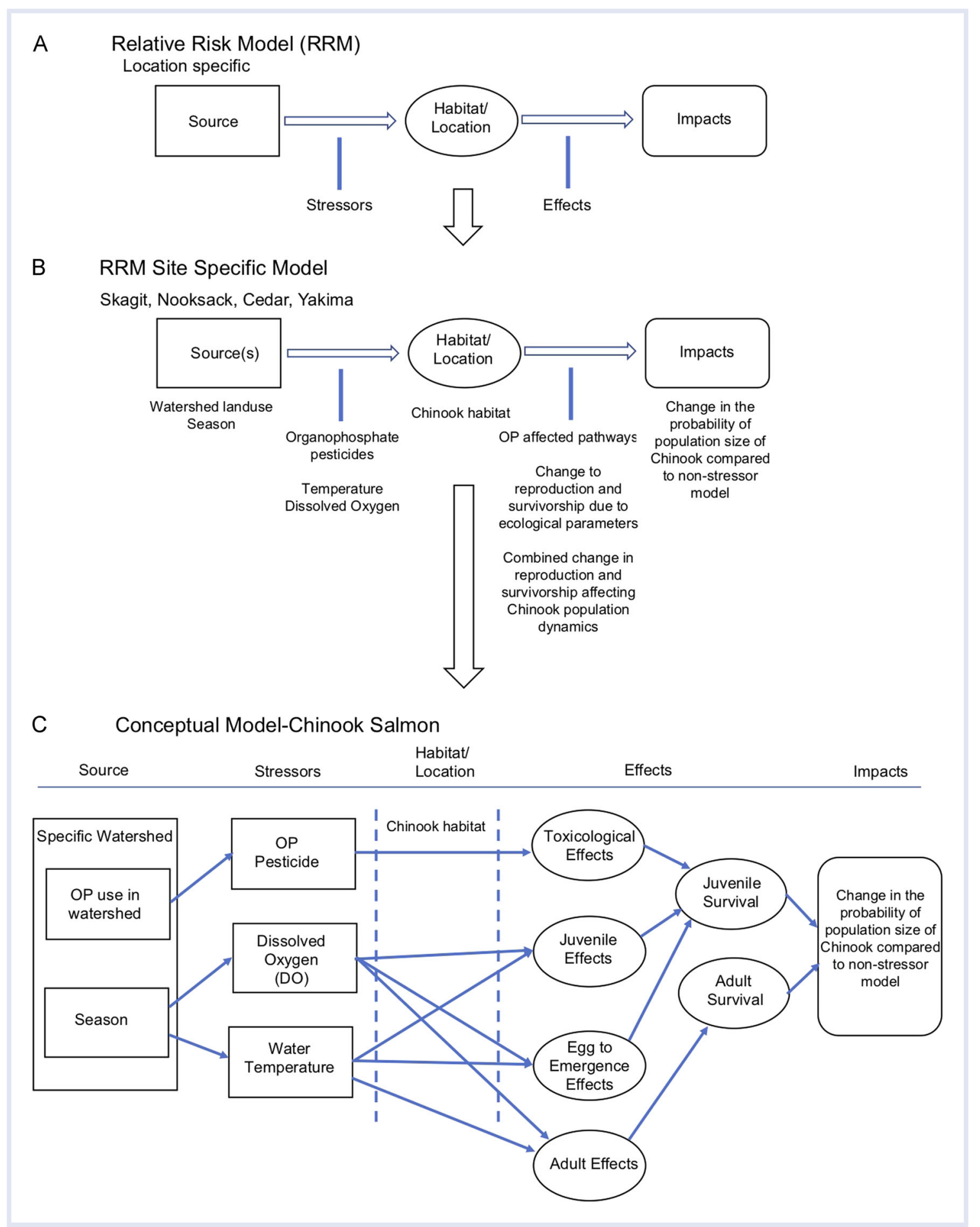

Figure 2. Derivation of the conceptual model for the BN-RRM to estimate risk. BN-RRM = Bayesian network relative risk model; OP=organophosphate.

distributions based on measurements or outcomes. The distribution of population sizes can be found in the Chinook Population Size node (4).

Estimation of risk. The estimate of risk to the endpoint was based on the management goal of no net loss of the Chinook population. Risk was therefore defined in the present study as the probability that the population is below that goal. In our simulations, the starting point for the population was 500000 individuals, and any number below that was defined as a net loss. There were 2 ways to display the outcome. The first was to present the probability distributions of those states below the management criterion. The second was to calculate a summary risk value by summing the probabilities of those states below the management goal of 500000 . 


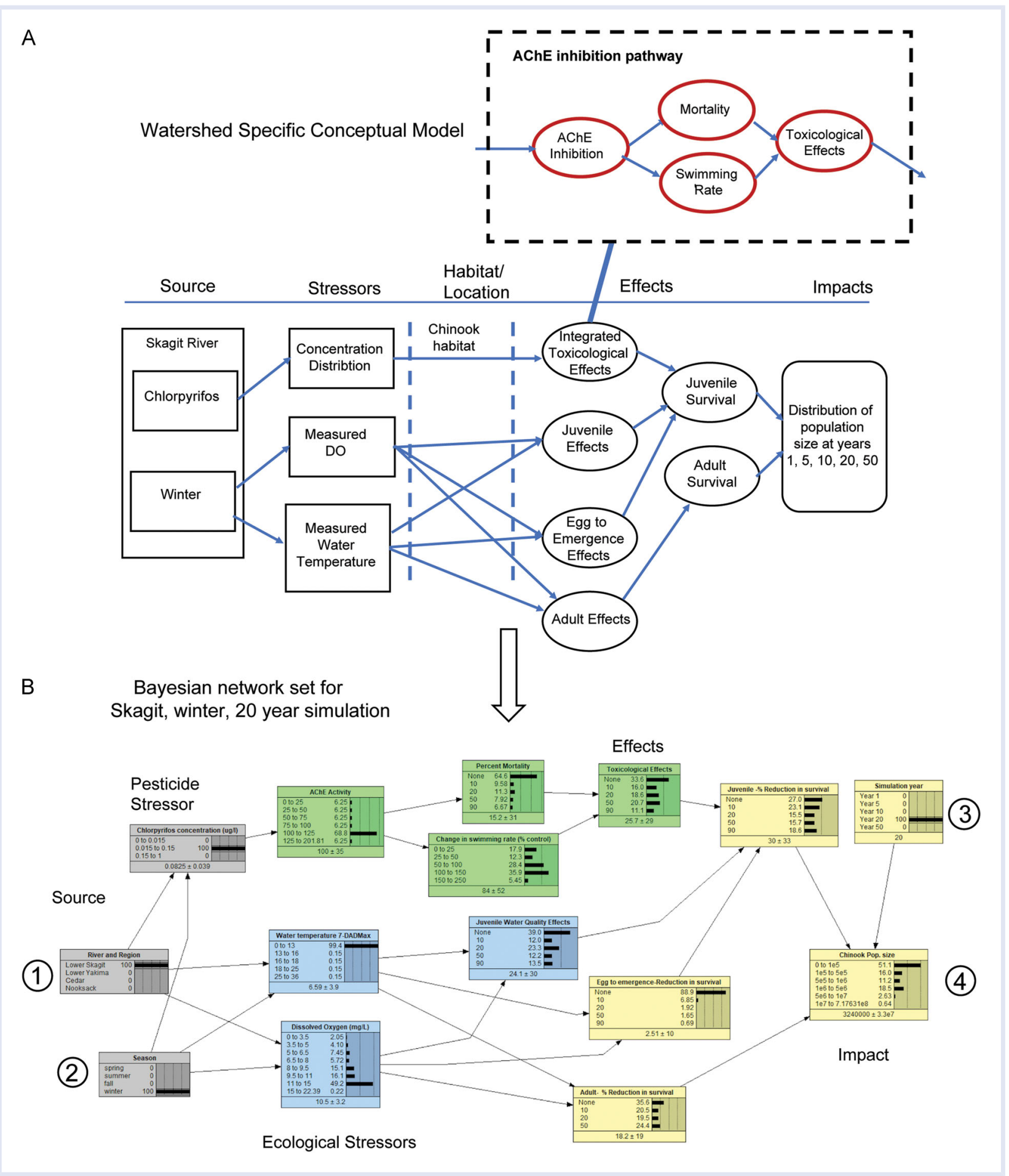

Figure 3. Conceptual model conversion to Bayesian network. The AChE Inhibition-Mortality-Swimming Rate pathway is part of the integrated Toxicological Effects node segment of the conceptual model (A). The final Bayesian network is illustrated in (B). Figure S2 in the Supplemental Data is a larger version of the diagram of the Bayesian network and the Netica model is also available. Node number 1 selects the river and node number 2 selects the season for the data sets for ecological stressors and pesticide concentration. Node number 3 selects the length of the simulation to be presented. Node 4 is the output of the probability of each population size given the conditions in nodes 1, 2, and 3. AChE = acetylcholinesterase; DO = dissolved oxygen.

Derivation of the population modeling to estimate risk. The population model was modified from Baldwin et al. (2009) for ocean-type Chinook salmon, incorporating demographic information from Columbia River populations. The RAMAS GIS 6 software (Akçakaya and Root 2013) was used to run the simulations for a 50-y period. The model included the standard deviations for each of the parameters, and a Monte Carlo analysis was conducted to select the value of each parameter for each model iteration (year). The original Baldwin formulation was modified to produce the output 
necessary to build the conditional probability tables (CPTs) for translating toxicological and environmental factors into probability distributions for Chinook population size at specific time intervals. That derivation, the Baldwin-Mitchell Model, is subsequently referred to as "BMM." A detailed description of the approach was described in Mitchell (2018). The approach is summarized in the following paragraphs and in more detail in the Supplemental Data section Population Modeling and Derivation of the BaldwinMitchell Model.

To incorporate a distribution of outcomes for each juvenile and adult survival reduction scenario, we collected the raw output of each RAMAS simulation. All of the possible scenarios of the 2 input nodes (Adult \% Reduction in Survival and Juvenile \% Reduction in Survival) were modeled. The raw output contained the abundance of individuals in each modeled population for each of the 200 replications after each $1-y$ iteration of the projection. For scenarios in which the population never went extinct, this resulted in 200 possible population abundances for each year of the 50-y projection. In scenarios in which the intrinsic rate of increase was less than 1, local (subpopulation) and ultimately metapopulation extinction usually occurred. This extinction resulted in fewer total values for population abundance.

Chinook population size distributions for discrete simulation years $1,5,10,20$, and 50 were drawn from the raw population simulation data and incorporated into CPTs. This allowed Chinook population size to be projected at specific time intervals through the BN. Within the CPTs, population sizes were binned into the following size ranges: 0 to $100000 ; 100000$ to 500000 ; 500000 to $1000000 ; 1000000$ to $5000000 ; 5000000$ to 10000000 ; and 10000000 to 720000000 . The BN-RRM endpoint node Chinook Population Size indicated the probability, based on population model simulations, that the Chinook population size for a given population would fall into one of these bins.

\section{Data sources and derivation of the nodes}

The data used to set the values for the parent nodes were obtained from a variety of sources. Table S1 in Supplemental Data has a description of each node and the derivation of the applicable CPT.

Derivation of the CPT. Conditional probability tables for the child nodes were derived using 4 categories of methods: empirical evidence, mathematical or biological equations, case file learning, and expert judgment (Marcot et al. 2006; Marcot 2017; Pollino et al. 2007; Chen and Pollino 2012). In a single model, CPTs for different nodes could be completed using different methods, or a combination of methods may be used within a single CPT (Pollino et al. 2007; Chen and Pollino 2012). The limitations and caveats for each of these methods are described by Marcot (2017).

The development of the CPTs for this BN relied on using all of these methods. In many instances, empirical data were used to derive mathematical equations or the relationships derived from case file learning. For example, the node AChE Activity was derived from an exposure-response equation based on laboratory measurements of enzyme inhibition in salmonids after exposure to $\mathrm{CH}$. The values in the node Change in Swimming Rate (\% Control) were determined from a data set and case learning.

Table 1 presents an example of how 4 of the nodesChlorpyrifos Concentration, Water Temperature, Juvenile Swimming Rate, and Adult \% Reduction in Survival-and their CPTs were derived. Details for all of the nodes are found in Supplemental Data Table S1. First, a short description of each node is provided, along with the categories used for discretization. The next column provides the justifications for the ranking criteria, and the far-right column lists the sources of the data used in constructing the nodes. For the Chlorpyrifos Concentration node, the data were actual concentrations detected in water samples collected from the watershed. The states assigned to specific ranges of $\mathrm{CH}$ concentrations were based on regulatory criteria for the protection of the salmonid species. The concentration of $\mathrm{CH}$ in the Nooksack River watershed was not measured in the winter season; therefore an equal probability distribution was used to describe the concentration of $\mathrm{CH}$ in the winter simulations. All the other watersheds had complete data sets.

The effect of cholinesterase inhibition on juvenile swimming rate was derived from the data generated by Sandahl et al. (2005) and Table 1. Coho salmon were the test species, and $\mathrm{CH}$ was the OP. The NOAA data set was kindly supplied by CA Laetz for an updated analysis by our team. The analysis used the drc package in $\mathrm{R}$ to estimate the regression (Ritz et al. 2015).

In the case of the Adult \% Reduction in Survival node, the states were obtained from the scientific literature describing the effects of DO and temperature on salmonid survival. In the Water Temperature node, the distribution of ranges was obtained from direct temperature measurements taken in the specific river in a given season. For the Adult \% Reduction in Survival node the data for ecological and toxicological pathways that affect adult salmonid survival were obtained from the scientific literature and case file learning.

The CPT for the Chinook population distribution was determined from the output of the BMM population model. An age-structured population model was constructed to predict the distribution of predicted population sizes across a set of discrete years. Case files were constructed based on 200 runs for each combination of values from the Juvenile \% Reduction in Survival and the Adult \% Reduction in Survival nodes for years $1,5,10,20$, and 50, resulting in 24388 cases. This output was analyzed using the case file function of Netica to obtain the values used in the CPTs based on field data.

Once all of the information was placed in the parent nodes and the CPTs were completed for the child nodes, the model was run and the results evaluated to verify the model structure and calculations. The completed BN-RRM can be downloaded from the Supplemental Data. 


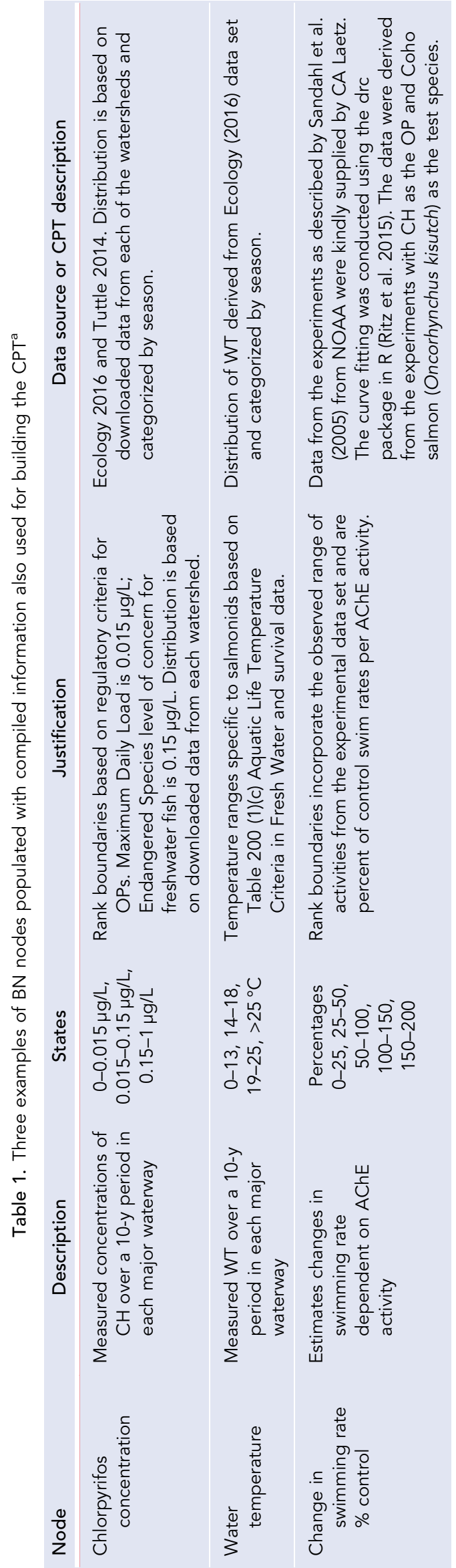

Sensitivity analysis. Sensitivity analysis explains the extent to which an endpoint node is influenced by the values of the input nodes (Pollino et al. 2007; Marcot 2012). The sensitivity analysis is used to understand which variables contribute to the state of the endpoint (Hines and Landis 2014; Landis, Ayre et al. 2017). It can also be used to identify variables that are important for future monitoring efforts or risk management actions (Hines and Landis 2014; Landis, Ayre et al. 2017). If data are unavailable for a variable and a uniform distribution is assigned to the node, the uncertainty will likely be reflected in the sensitivity analysis.

A sensitivity analysis was performed for the Chinook Population Size node for each watershed under different seasonal conditions, examining the influence of the input parameters on the endpoint node (Sensitivity to Findings [Norsys 2014]). Because the states are discrete, sensitivity was measured as mutual information (Woodberry et al. 2004; Pollino et al. 2007; Norsys 2014).

\section{RESULTS}

Risk

Risk was calculated as the probability of the Chinook salmon population being below the 500000 target defined as a net loss in the Chinook population. As examples, we presented risk to salmonid populations based on 6 scenarios occurring at the 20-y simulation time. The 6 scenarios were: 1) the BMM using the baseline parameters, 2) the BMM with a $20 \%$ reduction in survivorship of juveniles and adults, and 3-6) the BMM using the survival of juveniles and adults in each of the 4 watersheds (Nooksack, Cedar, Skagit, and Yakima) in the winter season.

In Figure 4A we compared the probability distribution of each population size category for Year 20 of the BMM baseline, the BMM model with the $20 \%$ reduction in survival of juveniles and adults, and the Chinook population survival in the Skagit River watershed. The dashed line represents the management goal of maintaining a Chinook population of 500000 fish.

All scenarios had a probability of not meeting the management goal. For the BMM using the Baldwin et al. (2009) baseline, the risk was a $2.43 \%$ probability. The BMM representing a $20 \%$ reduction in survivorship scenario had a $91.8 \%$ probability of not meeting the goal, leaving only an $8.2 \%$ probability of there being greater than 500000 Chinook. The Skagit-winter conditions scenario had a $67.3 \%$ probability of not meeting the goal. It also had the probability of being at the lowest population size of the 3 scenarios.

In comparing risk among all 6 scenarios (Figure 4B), the BMM baseline had the lowest risk, the BMM 20\% reduction in survivorship scenario had the highest, and the 4 watershed scenarios had a risk between $60 \%$ and $70 \%$ under winter conditions. Overall risk during summer conditions was higher.

Table 2 is a comparison of risk between the 4 watersheds for both winter and summer conditions, as well as the 


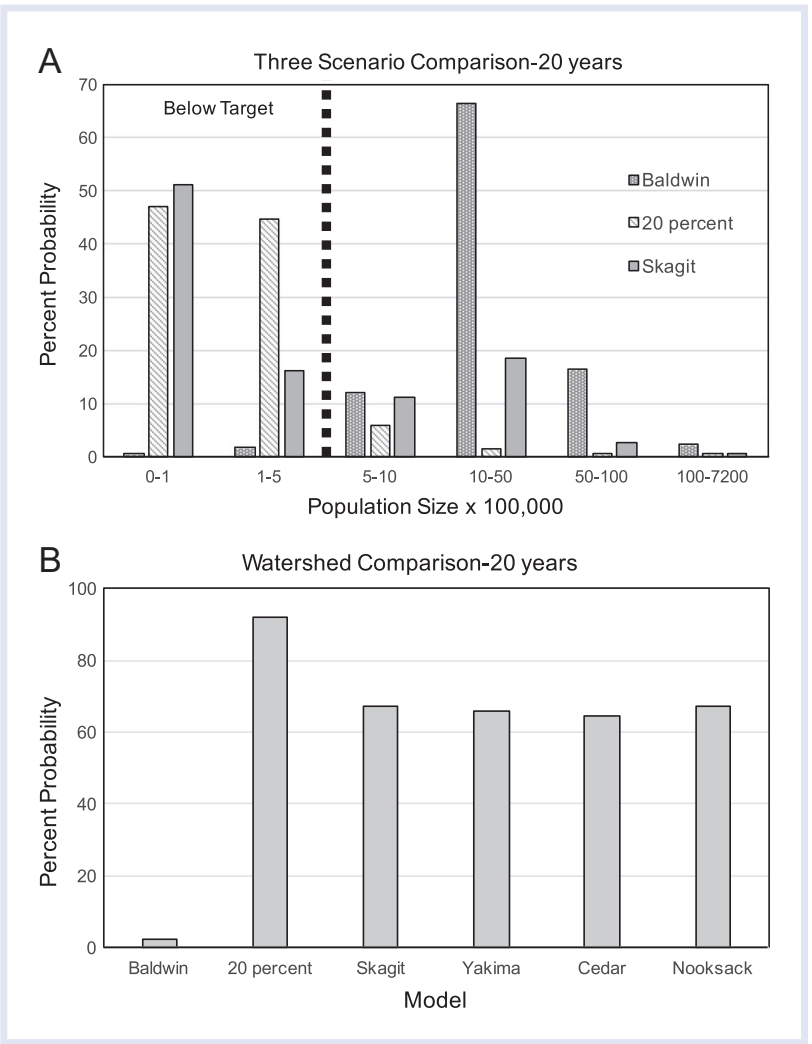

Figure 4. Model results for Chinook population size and risk. A comparison was made of the probability of population size scenarios: the BMM baseline, no additional stressor effects; the BMM with $20 \%$ reduction in survivorship; and the Skagit risk calculation with the BMM based on site-specific conditions (A). The dashed vertical line is the management goal. A comparison was made of risk for scenarios in which population levels were below 500000 for each of the model conditions: the BMM baseline, the BMM with a $20 \%$ reduction in survivorship, and the current BMM predictions for the Skagit, Yakima, Cedar, and Nooksack river watersheds, Washington, USA (B). $\mathrm{BMM}=$ Baldwin-Mitchell Model.

contributions of $\mathrm{CH}$ and ecological factors (DO, WT) to that risk. In each case, risk was highest in the summer. In every scenario, the ecological factors were the highest contributors to risk, ranging from $97.3 \%$ in the Nooksack River watershed under summer conditions to the lowest in the Cedar River watershed under winter conditions at $79.5 \%$. The contribution of $\mathrm{CH}$ to risk was highest in the Cedar River-winter scenario (20.5\%) and lowest in Nooksack Riversummer $(2.7 \%)$ scenario.

One of the properties of constructing the BN models in Netica is that they can be used to calculate the states in the model that would result in meeting a specific management goal. The change in these states would be derived from changes in management of the use of the pesticides and to improve water quality. In this example, the goal is a $100 \%$ probability of having at least a Chinook population size of 500000 fish. Using the Skagit River Chinook-winter model as an example, we set the Chinook Population Size node to $100 \%$ probability for the 500000 to 1000000 state. The node states that would result in this output were calculated (see Supplemental Data Figure S3). Table 3 is a comparison of the probability distributions for the nodes Juvenile \% Reduction in Survival, Toxicological Effects, Egg to Emergence Reduction in Survival, and Adult \% Reduction in Survival. To achieve the management goal, the distributions in each node were shifted among none, $10 \%$, and $20 \%$ effect states. Based on the recalculated model output, the Egg to Emergence Reduction in Survival has to reach a $92.6 \%$ probability of the zero state (i.e., no more than a $7.4 \%$ probability of egg to fry emergence reduction in survival) to achieve the set management goal. Changes also occur in the probability distributions of the states in the other nodes.

\section{Sensitivity analysis}

The model sensitivity was evaluated by calculating the mutual information contributions to the Chinook Population Size node using the Netica algorithm. We present the rankings of the important variables in Table 4 for the summer and winter seasons for the Cedar and Skagit rivers. The rank order of those variables important in estimating risk were identical in the 4 scenarios, with Juvenile \% Reduction in Survival first and Adult \% Reduction in Survival

Table 2. Comparison of risk with and without the OP under winter and summer seasonal conditions ${ }^{\text {a }}$

\begin{tabular}{|c|c|c|c|c|c|}
\hline Scenario ${ }^{b}$ & Risk & No OP & Change in risk & OP percent risk & Ecological percent risk \\
\hline Skagit-winter & 67.3 & 54.7 & 12.6 & 18.7 & 81.3 \\
\hline Skagit-summer & 80.2 & 72.7 & 7.5 & 9.4 & 90.6 \\
\hline Nooksack-winter & 67.3 & 55.0 & 12.3 & 18.3 & 81.7 \\
\hline Nooksack-summer & 92.4 & 89.9 & 2.5 & $2.7^{\mathrm{a}}$ & $97.3^{\mathrm{a}}$ \\
\hline Cedar-winter & 64.5 & 51.3 & 13.2 & $20.5^{a}$ & $79.5^{a}$ \\
\hline Cedar-summer & 81.8 & 74.8 & 7.0 & 8.6 & 91.4 \\
\hline Yakima-winter & 65.8 & 53.1 & 12.7 & 19.3 & 80.7 \\
\hline Yakima-summer & 85.3 & 79.8 & 5.5 & 6.4 & 93.6 \\
\hline
\end{tabular}

OP = organophosphate.

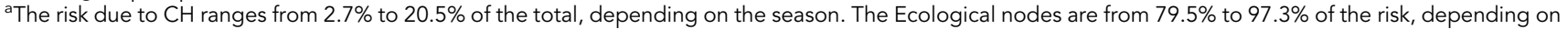
site and season.

bWatersheds in Washington, USA. 
Table 3. Comparison of node distributions from current conditions to meeting management goals ${ }^{\mathrm{a}}$

\begin{tabular}{|c|c|c|c|c|c|c|c|c|}
\hline \multirow[b]{2}{*}{$\begin{array}{l}\text { Effect } \\
\text { level }\end{array}$} & \multicolumn{2}{|c|}{$\begin{array}{c}\text { Juvenile } \% \text { reduction in } \\
\text { survival }\end{array}$} & \multicolumn{2}{|c|}{ Toxicological effects } & \multicolumn{2}{|c|}{$\begin{array}{l}\text { Egg to emergence } \\
\text { reduction in survival }\end{array}$} & \multicolumn{2}{|c|}{ Adult $\%$ reduction in survival } \\
\hline & Skagit-winter & $\begin{array}{c}\text { Management } \\
\text { goal }\end{array}$ & Skagit-winter & $\begin{array}{c}\text { Management } \\
\text { goal }\end{array}$ & Skagit-winter & $\begin{array}{l}\text { Management } \\
\text { goal }\end{array}$ & Skagit-winter & $\begin{array}{l}\text { Management } \\
\text { goal }\end{array}$ \\
\hline None & 27.10 & 41.10 & 33.60 & 42.20 & 88.90 & 92.60 & 35.60 & 44.60 \\
\hline 10 & 23.10 & 36.40 & 16.10 & 19.50 & 6.85 & 5.95 & 20.50 & 34.20 \\
\hline 20 & 15.50 & 21.10 & 18.50 & 20.90 & 1.92 & 1.00 & 19.50 & 20.20 \\
\hline 50 & 15.70 & 1.08 & 20.70 & 13.60 & 1.65 & 0.09 & 24.40 & 1.00 \\
\hline 90 & 18.50 & 0.31 & 11.10 & 3.61 & 0.69 & 0.78 & - & - \\
\hline
\end{tabular}

aThe table compares the values of the nodes between the Skagit River, Washington, USA under winter conditions with those calculated to reach the management goal to have a $100 \%$ probability of 500000 Chinook in the population. The change results in a shift in the distribution to none and lower levels compared to the values currently calculated for Chinook in the Skagit River.

second. This ranking order is expected because these are the 2 intermediary nodes to the Chinook Population Size node and are critical variables in the calculation of population dynamics. In the summer season, the third variable was Egg to Emergence and in the winter, Toxicological Effects. The rank order of the first 5 variables for the winter were identical between the 2 rivers; these variables are
Juvenile \% Reduction in Survival, Adult \% Reduction in Survival, Toxicological Effects, Juvenile Water Quality, and Percent Mortality.

\section{Uncertainty}

Regan et al. (2002, 2003) outlined a taxonomy of uncertainty for conservation biology and population modeling

Table 4. Sensitivity analysis for the Cedar and Skagit Rivers, Washington, USA for 2 seasons as calculated for the Chinook Population Size node ${ }^{a}$

\begin{tabular}{|c|c|c|c|c|c|}
\hline \multicolumn{3}{|c|}{ Cedar River } & \multicolumn{3}{|c|}{ Skagit River } \\
\hline Season & Node & $\%$ mutual information & Season & Node & $\%$ mutual information \\
\hline \multirow[t]{8}{*}{ Summer } & Juvenile \% reduction & 30.4 & Summer & Juvenile \% reduction & 30.6 \\
\hline & Adult \% reduction & 15.8 & & Adult $\%$ reduction & 16.3 \\
\hline & Egg to emergence & 9.55 & & Egg to emergence & 9.76 \\
\hline & WT & $4.8^{\mathrm{b}}$ & & Juvenile water quality & 3.49 \\
\hline & DO & $3.33^{b}$ & & DO & $4.61^{b}$ \\
\hline & Toxicological effects & $2.85^{c}$ & & WT & $4.03^{b}$ \\
\hline & Juvenile water quality & 2.76 & & Toxicological effects & $2.89^{c}$ \\
\hline & Percent mortality & 1.2 & & Percent mortality & 1.22 \\
\hline \multirow[t]{8}{*}{ Winter } & Juvenile \% reduction & 20.6 & Winter & Juvenile \% reduction & 20.4 \\
\hline & Adult $\%$ reduction & 16.8 & & Adult \% reduction & 18.2 \\
\hline & Toxicological effects & $4.51^{\mathrm{c}}$ & & Toxicological effects & $4.18^{c}$ \\
\hline & Juvenile water quality & 4.12 & & Juvenile water quality & 4.23 \\
\hline & Percent mortality & 1.87 & & Percent mortality & 1.73 \\
\hline & Change in swimming rate & 0.875 & & DO & $1.27^{\mathrm{b}}$ \\
\hline & AChE activity & 0.188 & & Change in swimming rate & 0.812 \\
\hline & DO & $0.159^{b}$ & & Egg to Emergence & 0.917 \\
\hline
\end{tabular}

$\mathrm{AChE}=$ acetylcholinesterase; $\mathrm{DO}=$ dissolved oxygen; $\mathrm{WT}=$ water temperature

${ }^{a}$ As measured by percent mutual information, the importance of some of the nodes changes, depending on season. In summer, the nodes Juvenile \% Reduction in Survival, Adult \% Reduction in Survival, and Egg to Emergence in Survival were the same order for the Cedar and the Skagit rivers. Egg to Emergence was not ranked in the Cedar and was ranked last in the Skagit.

${ }^{b}$ The importance of the ecological variables WT and DO was higher in the summer compared to the winter.

${ }^{\mathrm{c}}$ Toxicological Effects were ranked 6th in the Cedar and 7th in the Skagit. In winter, Toxicological Effects ranked 3rd. 
that we used. This section describes the epistemic and linguistic uncertainty in the risk assessment.

\section{Epistemic uncertainty}

Each of the watersheds have been extensively sampled and monitored over the years using similar sampling methods and analytical techniques, resulting in long-term comprehensive data sets. Therefore, seasonal and yearly variability in the $\mathrm{WT}, \mathrm{DO}$, and $\mathrm{CH}$ concentrations are well documented for each of the study sites. Uncertainty does exist in understanding the variability in the data within a watershed. For example, 1 source of data uncertainty was due to the limitation on the number of sampling sites compared to the extensive size of each study area. As such, our input distributions likely were underestimates of the total natural variability within each system.

We used Coho salmon as a surrogate for Chinook in the toxicity analysis because of the availability of Coho toxicological data. The AChE sensitivity and its relationship to swimming speed and toxicity are all based on a Coho model. Hence interspecific differences in sensitivity are not known. Experimental variability is also a factor, and the regressions of the exposure-response relationship are unlikely to capture all of that uncertainly. The CPTs derived from these regressions reflect that uncertainty.

\section{Model uncertainty}

Risk assessment model. In common with all models of ecological structures, our model is at best an abstraction of the processes that control the salmon population. We do include a series of key stressors, but in addition to $\mathrm{CH}$ at least 2 other OPs can be found in water samples. The variables WT and DO do not represent the variability in habitat, water flows, nutrients, and other characteristics of the watersheds.

Even with the limited number of variables in this model, we used a variety of tools to describe the interactions between variables. In multiple cases, as shown in Supplemental Data Table S1 that describes the nodes, no information was available on how WT and DO interact with AChE toxicity to determine an increase in mortality for the different life stages of Chinook salmon. In such instances, a "pegging the corners" approach is used. The known quantities are placed in the corners of the conditional probability table and the values are extrapolated to fill the other entries. This approach is an admission that we do not have any better information or "prior" with which to describe the interactions.

Population model. The uncertainties as described in Baldwin et al. (2009) are carried into our formulation. There are also the issues of downscaling from a regional formulation as in Baldwin to a watershed scale model as in the BMM. We do not have the information for these watersheds to describe specific life history characteristics except, perhaps, for the Yakima.
We also assume that there is a single Chinook population for each of the rivers. For the Yakima River it is understood that the Chinook salmon exist as a collection of patchy populations, even a metapopulation. Studies are currently underway to examine how the Yakima populations interact and how risk varies in the watershed (Mitchell 2018).

\section{Linguistic uncertainty}

The adoption of Chinook salmon population size as the BN-RRM endpoint reflects the priority of the Puget Sound Partnership for the recovery of Puget Sound. The criterion is no net loss, yet there are no specifications on how to do that for the Nooksack, Skagit, and Cedar watersheds. Criteria do, however, exist for the Yakima watershed and for its tributaries. This lack does lead to an uncertainty regarding whether or not we have adequately described the management goal for those watersheds.

The use of an initial population size of 500000 also is a source of linguistic uncertainty. The number sounds high, but only $0.3 \%$ or 1382 of the population are adults returning to spawn. Readers not familiar with the structure of salmon populations may interpret the 500000 as representing a larger overall population of reproductive and harvestable fish.

\section{DISCUSSION}

The goal of the present study was to demonstrate that a BN-RRM could be constructed to incorporate pesticide toxicity, described as the biomarker AChE inhibition, environmental variables, and a population model to calculate risk to Chinook salmon populations in Puget Sound. The successful construction and analysis of the models led to a number of insights into the risk assessment process and into the risk of pesticides and environmental stressors to Chinook populations.

The effects of environmental concentrations of $\mathrm{CH}$ in streams can contribute up to $20 \%$ of the risk to Chinook salmon population survival. However, this risk is dependent upon the watershed and the season. In our study, only $\mathrm{CH}$ was used in the models; however, other OP pesticides have been measured in each of these systems. We are now building models to incorporate these OPs as well.

Our initial expectation was that important differences in risk would be present in the 4 watersheds. In contrast to our expectations, the risk was similar among the 4 river systems. The 4 systems vary from urban (Cedar River watershed) to agricultural (Skagit, Nooksack, and Yakima river watersheds). Additionally, the Yakima River is part of the Columbia River Basin, not a Puget Sound watershed.

The incorporation of the AChE Inhibition node into the model was to describe the initiating event for the estimation of molecular, physiological, and organismal effects. Chlorpyrifos concentrations in each of the watersheds were low, but there were still effects that could be directly linked to a potential change in survivorship of juvenile and adult Chinook. The addition of a biomarker representing such a key event has the advantage of allowing synergistic and 
antagonistic interactions of OPs to be described as a net change in AChE inhibition.

To prevent any net loss in the Chinook population, multiple factors need to be addressed. Given the current model, the Egg to Emergence Reduction in Survival node has to meet a $92.6 \%$ probability of being in the zero state to achieve the management goal for Chinook salmon populations. That node is influenced by both the ecological and toxicological effects pathways, depending upon the season, and both are important in determining risk.

As illustrated in Table 3, Juvenile \% Reduction in Survival, Toxicological Effects, Egg to Emergence Reduction in Survival, and Adult \% Reduction in Survival need to be prioritized for management action. The model indicates that the probability distributions for these variables need to be shifted toward the $0 \%$ to $20 \%$ states to meet the no net loss in Chinook population endpoint. The distributions in these nodes represent targets for the future management options for these watersheds.

\section{Context}

The model by Baldwin et al. (2009) was the basis of the population modeling used in the present study. We used the same parameters in determining rates of reproduction, growth, and survivorship. In the Baldwin et al. (2009) study, pulsed exposures to a pesticide followed by a $10 \%$ effect exposure did cause inhibition of population growth. Spromberg and Meador (2006) used a similar age-structure matrix population model to predict how low, environmentally comparable concentrations of toxicants could affect populations of Chinook, Coho, and sockeye salmon. Those authors found that a 10\% effect level did alter the population dynamics of each species, depending on their respective life history. Finally, an age-structured population model that also incorporated patch dynamics was used by Spromberg and Scholtz (2011) to examine the effects of prespawn mortality on Coho population dynamics. Their model results showed that effects in 1 stream could impact survival outcomes within the entire metapopulation.

Our results correspond with those results in that relatively small toxicological effects on individual organisms can lead to important changes in population survival. Our models indicated that toxicity was not the most important factor but that in certain circumstances it could be responsible for as much as $20 \%$ of the risk to Chinook population survival. Ecological stressors such as WT and DO were found to be critical in determining the risk. These results indicate the importance of understanding the broad suite of factors that when combined can cause increased impacts to the survival of the Chinook population.

We have demonstrated that a molecular initiating event (MIE), in this case AChE inhibition (Russom et al. 2014), can be incorporated into a risk assessment framework that includes a site-specific ecological context. The context includes other quantified ecological stressors and the life history characteristics of the population described in a probabilistic format. In addition, uncertainty is explicitly described for each $\mathrm{BN}$ node, whether it is the $\mathrm{MIE}$, a range of winter temperatures in the watershed, or other physical or chemical parameters.

\section{Model framework and limitations}

The intent of the present paper was not to perform a detailed ecological risk assessment of the 4 watersheds. The demonstration that the BN-RRM can be applied to landscapes of various types and sizes, with multiple stressors, interactions, and endpoints, has already been accomplished (Ayre and Landis 2012; Ayre et al. 2014; Hines and Landis 2014; Herring et al. 2015; Landis, Ayre et al. 2017).

Each of the 4 watersheds is subject to a multitude of other stressors, including loss of habitat, inputs of other types of pesticides, excess nutrients, and nonpoint surface runoff, as well as stream blockages and other factors that can affect salmon survivorship. There are also many other endpoints that can be considered as delineated by the PSP (2014). The case study we described in the present paper should not be construed as concluding that Chinook salmon population is the endpoint most at risk or that the pesticide or ecological factors are the major contributors of risk in each watershed. Such conclusions require a detailed risk assessment and comprehensive data sets of $\mathrm{CH}$ and $\mathrm{DO}$ concentrations and WT measurements to determine whether the risk to the Chinook salmon populations not meeting the management standard are apparent.

\section{Use of the Baldwin-Mitchell model}

We used the population model as developed by Baldwin et al. (2009) for the Chinook salmon and incorporated survivorship rates as experienced in the region under those ecological conditions. Those survivorship rates likely included the effects due to WT and DO concentrations at a basin-wide level. In the BMM and in the BN-RRM, we have not attempted to edit out those effects by altering the survivorship rates as originally formulated by Baldwin et al. (2009). We may be double-counting a portion of the effects due to the codependent relationship between the ecological factors, but it is not clear that there are sufficient data to parse out the effects due to WT and DO for the period that the Baldwin model was developed. We do add sitespecific details for the distributions of the ecological effects and in demonstrating the differences in seasonal variation.

\section{Adaptive management}

Recall that the ultimate purpose of a risk assessment is to make decisions in an adaptive management process. Wyant et al. (1995) described the role that ecological risk assessment could play in an adaptive management process. McDonald et al. (2015) had demonstrated that a BN could be used to describe a portion of the classic adaptive management process but did not include the other aspects described by Wyant et al. (1995). Van den Brink et al. (2016) further advanced the Wyant et al. (1995) construct by 
connecting ecological risk assessment, the analysis of Big Data, and BNs. Landis, Markiewicz et al. (2017) built a BNbased adaptive management process following the framework of Wyant et al. (1995) and Van den Brink et al. (2016), describing how it could be applied to a Hg-contaminated section of the South River, Virginia, USA.

The results of the present study can be applied to an adaptive management framework as well. We have demonstrated that ecological and molecular-based pathways can be combined to estimate population-scale risk. As described in Landis, Markiewicz et al. (2017), it is possible to estimate risk from inputs derived from laboratory and field measurements to generate a series of testable hypothesis. We also demonstrated that the model output can be reset to meet a management goal so that input conditions to meet that objective can be back-calculated. As additional data are obtained on WT and DO in the 4 watersheds, the probability distributions can be modified and risk recalculated. If more detailed or quantitative exposure-response information becomes available, for example, the effect of WT on AChE inhibition, the model can be easily updated and risk recalculated.

\section{Next steps}

The 4 river watersheds in our study area were also contaminated with malathion and diazinon OP pesticides. The logical next step in the present study would entail building a BN-RRM framework to conduct a 3-chemical risk assessment of the 4 watersheds. Similarly, population models are available for Coho salmon, a species with a very different life history strategy than Chinook, but similar physiology, and as such capable of easily being incorporated into the model. Differences in responses to WT and DO can be incorporated in a separate BN pathway and a species-specific CPT.

For example, sufficient details are available to describe distinct Chinook salmon populations in the Yakima River. Some of these populations are supplemented by hatchery fish, whereas others are from wild stocks. The interaction may be similar to patchy or metapopulation dynamics. Such a risk assessment would describe risk at a finer, localized scale than do our watershed-level-based descriptions. An adaptive management process could also be determined for the Yakima River and different management options examined for their ability to meet the long-term management goals for this watershed.

Acknowledgment-This research was supported by USEPA STAR Grant RD-83579501. Abigail Nickelson provided the site-specific data sets of the Washington Department of Agriculture. Cathy Laetz (NOAA) provided the data for calculating toxicity of the organophosphates. Julann Spromberg (NOAA) answered questions regarding the Baldwin et al. (2009) model that is a derivative of her model described in Spromberg and Meador (2006).

Disclaimer-We have no conflict of interest to declare. The peer-review process for this article was managed by the Editorial Board without the involvement of WG Landis.
Data Availability Statement-The Netica model is available as a download in Supplemental Data, as are the tables describing the nodes. The data sets we used to establish exposure-response curves, chemical concentrations, temperature, and dissolved oxygen are in the public domain. Our collection of this information can be found at the collection of Western Washington University Library at https://cedar.wwu.edu/esci_facpubs/60/.

\section{SUPPLEMENTAL DATA}

The .pdf file contains the tables, methods and graphics as called out in the text. The Bayesian network model file in Netica is denoted by the suffix .neta. The files are found in the permanent collection of Western Washington University at https://cedar.wwu.edu/esci_facpubs/60/.

BN Node Derivation and Quantification

Table S1. BN node derivation. BN = Bayesian network.

Population Modeling and Derivation of the BaldwinMitchell Model (BMM)

Figure S1. Life history graph representing ocean-type Chinook salmon with a maximum female age of 5 and reproductive ages of 3, 4, and 5 y (after Baldwin et al. 2009).

Table S2. Transition elements corresponding to the Chinook life history graph in Figure S1.

Table S3. Baseline survival values and calculations for reductions to juvenile survival and reductions to adult survival.

\section{Sensitivity Analysis Methods}

Figure S2. The Bayesian network with notes set for the Skagit River, Winter Season.

Figure S3. Use of BN-RRM to derive management goals.

\section{ORCID}

Katherine E von Stackelberg (1D https://orcid.org/0000-00029742-7398

\section{REFERENCES}

Akçakaya HR, Root WT. 2013. RAMAS GIS: Linking spatial data with population viability analysis. Version 6.0. Setauket (NY): Applied Biomathematics. $209 \mathrm{p}$.

Apitz SE. 2013. Ecosystem services and environmental decision-making Seeking order in complexity. Integr Environ Assess Manag 9:214-230.

Ayre KK, Caldwell CA, Stinson J, Landis WG. 2014. Analysis of regional scale risk to whirling disease in populations of Colorado and Rio Grande cutthroat trout using a Bayesian belief network model. Risk Anal 34: 1589-1605.

Ayre KK, Landis WG. 2012. A Bayesian approach to landscape ecological risk assessment applied to the Upper Grande Ronde watershed, Oregon. Hum Ecol Risk Assess 18:946-970.

Baldwin DH, Spromberg JA, Collier TK, Scholz NL. 2009. A fish of many scales: Extrapolating sublethal pesticide exposures to the productivity of wild salmon populations. Ecol Appl 19:2004-2015.

Bartolo RE, van Dam RA, Bayliss B. 2012. Regional ecological risk assessment for Australia's tropical rivers: Application of the relative risk model. Hum Ecol Risk Assess 18:16-46.

Barton DN, Kuikka S, Varis O, Uusitalo L, Henriksen HJ, Borsuk M, de la Hera A, Farmani R, Johnson S, Linnell JD. 2012. Bayesian networks in environmental and resource management. Integr Environ Assess Manag 8:418-429.

Carriger JF, Newman MC. 2011. Influence diagrams as decision-making tools for pesticide risk management. Integr Environ Assess Manag 8 339-350. 
Chen Q, Lui J, Ho KC, Yang Z. 2012. Development of a relative risk model for evaluating ecological risk of water environment in the Haihe River Basin estuary area. Sci Total Environ 420:79-89.

Chen SH, Pollino CA. 2012. Good practice in Bayesian network modelling. Environ Modell Softw 37:134-145.

Colnar AC, Landis WG. 2007. Conceptual model development for invasive species and a regional risk assessment case study: The European green crab, Carcinus maenas, at Cherry Point, Washington USA. Hum Ecol Risk Assess 13:120-155.

Conolly RB, Ankley GT, Cheng W, Mayo ML, Miller DH, Perkins EJ, Villeneuve DL, Watanabe KH. 2017. Quantitative adverse outcome pathways and their application to predictive toxicology. Environ Sci Technol 51:4661-4672

[Ecology] Washington State Department of Ecology. 2016. Environmental Information Management System, Version 2.0.0.0. Freshwater fish contaminants chlorpyrifos 2006-2016. Lacey (WA). [accessed 2019 May 8]. https://ecology.wa.gov/Research-Data/Data-resources/EnvironmentalInformation-Management-database

[Ecology] Washington State Department of Ecology. 2018. Washington State water quality assessment 303(d) and 305(b) list. Olympia (WA). [accessed 2019 Jul 24]. https://fortress.wa.gov/ecy/approvedwqa/ ApprovedSearch.aspx

Hanson N, Stark JD. 2012. Comparison of population level and individual level endpoints to evaluate ecological risk of chemicals. Environ Sci Technol 2012:5590-5598.

Harris MJ, Stinson JM, Landis WG. 2017. A Bayesian approach to integrated ecological and human health risk assessment for the South River, Virginia mercury contaminated site. Risk Anal 37:1341-1357.

Herring CE, Stinson J, Landis WG. 2015. Evaluating non-indigenous species management in a Bayesian networks derived relative risk framework for Padilla Bay, Washington. Integr Environ Assess Manag 11:640-652.

Hines EE, Landis WG. 2014. Regional risk assessment of the Puyallup River Watershed and the evaluation of low impact development in meeting management goals. Integr Environ Assess Manag 10:269-278.

Hooper MJ, Ankley GT, Cristol DA, Maryoung LA, Noyes PD, Pinkerton KE. 2013. Interactions between chemical and climate stressors: A role for mechanistic toxicology in assessing climate change risks. Environ Toxicol Chem 32:32-48.

Johns AF, Graham SE, Harris MJ, Markiewicz AJ, Stinson JM, Landis WG. 2017. Using the Bayesian network relative risk model risk assessment process to evaluate management alternatives for the South River and Upper Shenandoah River, Virginia. Integr Environ Assess Manag 13: 100-114.

Kanwar P, Bowden WB, Greenhalgh S. 2015. A regional ecological risk assessment of the Kaipara Harbour, New Zealand, using a relative risk model. Hum Ecol Risk Assess 21:1123-1146.

Kramer VJ, Etterson MA, Hecker M, Murphy CA, Roesijadi G, Spade DJ, Spromberg JA, Wang M, Ankley GT. 2011. Adverse outcome pathways and ecological risk assessment: Bridging to population-level effects. Environ Toxicol Chem 30:64-76.

Laetz CA, Baldwin DH, Collier TK, Hebert V, Stark JD, Scholz NL. 2009. The synergistic toxicity of pesticide mixtures: Implications for risk assessment and the conservation of endangered Pacific salmon. Environ Health Perspect 117:348.

Laetz CA, Baldwin DH, Hebert V, Stark JD, Scholz NL. 2013. Interactive neurobehavioral toxicity of diazinon, malathion, and ethoprop to juvenile Coho salmon. Environ Toxicol Chem 47:2925-2931.

Laetz CA, Baldwin DH, Hebert VR, Stark JD, Scholz NL. 2014. Elevated temperatures increase the toxicity of pesticide mixtures to juvenile Coho salmon. Aquat Toxicol 146:38-44.

Landis WG, Ayre KK, Johns AF, Summers HM, Stinson J, Harris MJ, Herring CE, Markiewicz AJ. 2017. The multiple stressor ecological risk assessment for the mercury contaminated South River and Upper Shenandoah River using the Bayesian network-relative risk model. Integr Environ Assess Manag 13:85-99.

Landis WG, Markiewicz AJ, Ayre KK, Johns AF, Harris MJ, Stinson JM, Summers HM. 2017. A general risk-based adaptive management scheme incorporating the Bayesian network relative risk model with the South River, Virginia, as case study. Integr Environ Assess Manag 13:115-126.

Landis WG, Wiegers JK. 1997. Design considerations and a suggested approach for regional and comparative ecological risk assessment. Hum Ecol Risk Assess 3:287-297.

Landis WG, Wiegers JK. 2007. Ten years of the relative risk model and regional scale ecological risk assessment. Hum Ecol Risk Assess 13:25-38.

Marcot BG. 2012. Metrics for evaluating performance and uncertainty of Bayesian network models. Ecol Modell 230:50-62.

Marcot BG. 2017. Common quandaries and their practical solutions in Bayesian network modeling. Ecol Modell 358:1-9.

Marcot BG, Steventon JD, Sutherland GD, McCann RK. 2006. Guidelines for development and updating Bayesian belief networks applied to ecological modeling and conservation. Can J For Res 36:3063-3074.

McDonald KS, Ryder DS, Tighe M. 2015. Developing best-practice Bayesian Belief Networks in ecological risk assessments for freshwater and estuarine ecosystems: A quantitative review. J Environ Manage 154: 190-200.

Miller DH, Tietge JE, McMaster ME, Munkittrick KR, Xia X, Griesmer DA, Ankley GT. 2015. Linking mechanistic toxicology to population models in forecasting recovery from chemical stress: A case study from Jackfish Bay, Ontario, Canada. Environ Toxicol Chem 34:1623-1633.

Mitchell CJ. 2018. Modeling the effects of pesticides and environmental stressors on spring chinook salmon populations in the Yakima river basin, WA [MS thesis]. Pullman (WA): Washington State Univ. 88 p. [accessed 2019 Jul 24]. http://www.dissertations.wsu.edu/Thesis/Summer2018/C_ Mitchell_080918.pdf

[Norsys] Norsys Software Corp. 2014. Netica Bayesian network development software. Vancouver (BC). [accessed 2019 Jun 12]. https://www.norsys. com/tutorials/netica/secC/tut_C3.htm

Nyberg JB, Marcot BG, Sulyma R. 2006. Using Bayesian belief networks in adaptive management. Can J For Res 36:3104-3116.

Pollino CA, Woodberry O, Nicholson A, Korb K, Hart BT. 2007. Parameterisation and evaluation of a Bayesian network for use in an ecological risk assessment. Environ Modell Softw 22:1140-1152.

[PSP] Puget Sound Partnership. 2014. The 2014/2015 action agenda for Puget Sound. Local ecosystem recovery-Skagit Watershed. Olympia (WA). [accessed 2019 Jul 24]. http://www.psp.wa.gov/downloads/2014_action_ agenda/LIO_Profiles/Skagit_Profile_20140408.pdf

Regan HM, Akcakaya HR, Ferson S, Root KV, Carroll S, Ginzburg LR. 2003. Treatments of uncertainty and variability in ecological risk assessment of single-species populations. Hum Ecol Risk Assess 9:889-906.

Regan HM, Colyvan M, Burgman MA. 2002. A taxonomy and treatment of uncertainty for ecology and conservation biology. Ecol Appl 12: 618-628.

Ritz C, Baty F, Streibig JC, Gerhard D. 2015. Dose-response analysis using R. PLOS ONE 10:e0146021.

Russom CL, LaLone CA, Villeneuve DL, Ankley GT. 2014. Development of an adverse outcome pathway for acetylcholinesterase inhibition leading to acute mortality. Environ Toxicol Chem 33:2157-2169.

Sandahl JF, Baldwin DH, Jenkins JJ, Scholz NL. 2005. Comparative thresholds for acetylcholinesterase inhibition and behavioral impairment in Coho salmon exposed to chlorpyrifos. Environ Toxicol Chem 24:136-145.

Sargeant D, Anderson P. 2010. Skagit-Samish Basin intensive surface water sampling for pesticides in salmon-bearing streams, 2009. A cooperative study by the Washington State Departments of Ecology and Agriculture. Publication 10-03-043, August 2010. Olympia (WA). [accessed 2019 Jul 24]. https://fortress.wa.gov/ecy/publications/documents/1003043.pdf

Spromberg JA, Meador JP. 2006. Relating chronic toxicity responses to population-level effects: A comparison of population-level parameters for three salmon species as a function of low-level toxicity. Ecol Modell 199:240-252.

Spromberg JA, Scholtz NL. 2011. Estimating the future decline of wild Coho salmon populations resulting from early spawner die-offs in urbanizing watersheds of the Pacific Northwest, USA. Integr Environ Assess Manag 4: 648-656.

Tuttle G. 2014. Surface water monitoring program for pesticides in salmonidbearing streams, 2013 data summary: A cooperative study by the Washington 
State Departments of Agriculture and Ecology. Washington State Department of Agriculture. August 2014. Report AGR PUB 103-411 (N/8/14). Olympia (WA). [accessed 2019 Jul 24]. https://fortress.wa.gov/ecy/publications/ documents/0603036.pdf

Uusitalo L. 2007. Advantages and challenges of Bayesian networks in environmental modelling. Ecol Modell 203:312-318.

Van den Brink P, Choung CB, Landis W, Pinto MM, Pettigrove V, Scanes P Smith R, Stauber J. 2016. New approaches to the ecological risk assessment of multiple stressors. Mar Freshwater Res 67:393-413.
Wiegers JK, Feder HM, Mortensen LS, Shaw DG, Wilson VJ, Landis WG 1998. A regional multiple stressor rank-based ecological risk assessment for the fjord of Port Valdez, AK. Hum Ecol Risk Assess 4:1125-1173.

Woodberry O, Nicholson AE, Korb KB, Pollino CA. 2004. Parameterising Bayesian networks. In: Webb GI, Xinghuo Y, editors. Al 2004: Advances in artificial intelligence: 17th Australian Joint Conference on Artificial Intelligence; 2004 Dec 4-6; Cairns, Australia. Berlin (DE): Springer. p 1101-1107.

Wyant G, Meganck RA, Ham SH. 1995. A planning and decision-making framework for ecological restoration. Environ Manage 19:789-796. 